\title{
Insights into the Role of the Habenular Circadian Clock in Addiction
}

\author{
Nora L. Salaberry ${ }^{\dagger}$ and Jorge Mendoza ${ }^{\star \dagger}$ \\ CNRS UPR-3212, Institute of Cellular and Integrative Neurosciences, University of Strasbourg, Strasbourg, France
}

Drug addiction is a brain disease involving alterations in anatomy and functional neural communication. Drug intake and toxicity show daily rhythms in both humans and rodents. Evidence concerning the role of clock genes in drug intake has been previously

OPEN ACCESS

Edited by:

Ryan Wellington Logan, University of Pittsburgh, USA

Reviewed by: Shashank Tandon, University of Utah, USA

Luigi Janiri,

Università Cattolica del Sacro Cuore,

Anton llango,

Leibniz Institute for Neurobiology,

Germany

*Correspondence:

Jorge Mendoza

jmendoza@inci-cnrs.unistra.fr

${ }^{\dagger}$ Nora L. Salaberry and Jorge Mendoza have contributed equally to

this work.

Specialty section:

This article was submitted to Addictive Disorders and Behavioral

Dyscontrol,

a section of the journal

Frontiers in Psychiatry

Received: 04 September 2015

Accepted: 07 December 2015

Published: 05 January 2016

Citation:

Salaberry NL and Mendoza J (2016)

Insights into the Role of the

Habenular Circadian Clock in

Addiction.

Front. Psychiatry 6:179.

doi: 10.3389/fpsyt.2015.00179 reported. However, the implication of a timekeeping brain locus is much less known. The epithalamic lateral habenula (LHb) is now emerging as a key nucleus in drug intake and addiction. This brain structure modulates the activity of dopaminergic neurons from the ventral tegmental area, a central part of the reward system. Moreover, the LHb has circadian properties: LHb cellular activity (i.e., firing rate and clock genes expression) oscillates in a 24-h range, and the nucleus is affected by photic stimulation and has anatomical connections with the main circadian pacemaker, the suprachiasmatic nucleus. Here, we describe the current insights on the role of the LHb as a circadian oscillator and its possible implications on the rhythmic regulation of the dopaminergic activity and drug intake. These data could inspire new strategies to treat drug addiction, considering circadian timing as a principal factor.

Keywords: circadian system, habenula, drug of abuse, addiction, dopamine

\section{THE CIRCADIAN SYSTEM}

Environmental signals are rhythmic and organisms have to adapt to daily changes imposed by the day-night alternation. Species have, therefore, developed timekeeping mechanisms that are regulated by circadian ( irca $=$ close to, dien $=$ day) clocks in almost any cell. These clocks are able to oscillate in a self-sustained manner with a periodicity close to a day $(24 \mathrm{~h})$, and to transmit time information to the rest of the body through specific output pathways (1).

The mammalian hypothalamus contains the principal circadian clock in the suprachiasmatic nucleus [SCN; (2)], which controls most of the behavioral and physiological rhythms (e.g., locomotor activity, hormone secretion). In every SCN cell, the clockwork is dependent on an oscillatory mechanism formed from transcription-translational feedback loops in which the expression of clock genes like, Clock, Bmal1, Per (1-3), Cry (1-2), and Rev-erbo, and their respective proteins, runs around $24 \mathrm{~h}(3)$.

Abbreviations: CPP, conditioned preference place; DA, dopamine; DBS, deep brain stimulation; FR, fasciculus retroflexus; $\mathrm{Hb}$, habenula; LHb, lateral habenula; MHb, median habenula; $\mathrm{mPFC}$, medial prefrontal cortex; NAc, nucleus accumbens; PK2, prokineticine2; RMTg, rostromedian tegmentum nucleus; SCN, suprachiasmatic nucleus; VTA, ventral tegmental area. 
Light is the most important synchronizer for the SCN, this relays on a direct pathway from the photosensitive retinal ganglion cells that use the photopigment melanopsin (4). Besides light stimulation, non-photic time cues, such as exercise, food restriction, or drug intake, are able to affect or synchronize the SCN clock activity as well (5-7).

\section{THE CLOCK ON DRUGS}

In humans and animals, drug intake often results in disruptions of daily rhythms [e.g., locomotor activity, sleep-wake cycle, eating habits; $(5,8)$ ]. In rodents, several drugs of abuse like methamphetamine, cocaine, ethanol, and morphine affect the period of circadian rhythms of behavior and physiology [e.g., locomotion, body temperature $(5,8,9)]$.

Furthermore, people with perturbations of the circadian system [e.g., shift-workers, people experiencing frequent jet-lags; (10)], or animal models with disruptions of the body clock [e.g., chronic jet-lag exposure; (11)] show an increase of drug intake (e.g., psychostimulants). For example, shift-workers use methamphetamine to avoid sleepiness and perform tasks accurately during their working hours. Methamphetamine intake occurs mainly at the beginning of the active phase regardless of the day-night period (10), suggesting that drug intake may have a synchronizer role for the circadian clock (8).

Reciprocally, the circadian system modulates the behavioral responses to drug intake. In some clinical reports drug overdoses and toxicity have been showed to be clock-dependent (12-14). In rodents, behavioral sensitization and reward responses (measured by a conditioned place preference, CPP) to chronic injections of cocaine are significantly higher when animals are treated in the early day than at dusk or night $(15,16)$. Furthermore, some studies showed that the hormone melatonin, which is secreted at night, modulates the day-night variations in cocaine sensitization and CPP in mice (16-19).

In rats, cocaine self-administration or alcohol intake shows a daily rhythm with higher consumption during the night (20-22). Nonetheless, for cocaine, daily rhythms are observed only when access is restricted to two or three intakes per hour. Over three intakes/h drug intake increases and the rhythm is disrupted (20). Interestingly, under constant darkness conditions, a circadian rhythm of cocaine intake emerges with a higher consumption at night, indicating that an endogenous clock regulates the circadian activity of cocaine intake (23).

Circadian genes from the molecular clockwork regulate drug intake and drug-related behaviors. Mutations of the genes Per2 or Clock (e.g., Clock ${ }^{\Delta 19}$ mice) lead to higher behavioral responses (e.g., CPP and behavioral sensitization) to chronic injections of cocaine, and an increase in alcohol consumption (15, 24-26). Interestingly, animals lacking the gene Per1 or Npas2 (a homolog of the Clock gene) are behaviorally less sensitive to cocaine (15, 27), showing opposite effects to drug intake to those observed in Per2 and Clock mutants. Together, these data suggest an important link between drug intake, the circadian system, and the master clock in the SCN.

Although the SCN is the principal pacemaker, other circadian oscillators in the brain and peripheral organs are present
(28). More importantly, in brain structures regulating reward and behavior, circadian oscillations with a similar molecular machinery to the SCN have been reported (28-30). This suggests that, beyond the SCN, a multi-oscillatory circadian system in the mammalian brain composed of the reward centers, inter alia, may regulate behavior and drug intake (31).

\section{THE HABENULA}

The habenula $(\mathrm{Hb})$ is a brain region, which with the pineal gland forms the epithalamus. It is an interesting structure involved in the control of behavior (32). The $\mathrm{Hb}$ is located dorsally along the third ventricle close to the dorso-medial thalamus. It is mainly divided into two regions: the median $\mathrm{Hb}(\mathrm{MHb})$ and the lateral $\mathrm{Hb}(\mathrm{LHb})$ nuclei. Both regions receive forebrain information via the fibers of the stria medullaris and project to the midbrain via the efferent fibers of the fasciculus retroflexus (FR). The $\mathrm{MHb}$ and LHb contain sub-nuclei that differ in their receptors, cell morphology, anatomical and functional inputs and outputs, and neurotransmitters (33-36).

The LHb is a relay structure and, according to Hikosaka (37), its role is mainly related to the suppression of motor activity. However, several studies showed that the LHb is involved in other brain functions, such as reward, aversion, cognition, maternal behavior, sleep, and circadian rhythms, and in brain dysfunctions, such as addiction, depression, and schizophrenia (35-38).

\section{The LHb in the Dopamine Circuitry: Implications in Addiction}

The reward system is an intricate network involving diverse structures. The keystone of this circuit is the communication between the ventral tegmental area (VTA) and the nucleus accumbens (NAc). Dopaminergic neurons of the lateral VTA, which project to the lateral part of the NAc, encode for reward or for aversion depending on the dopamine (DA) receptors involved (39). Few studies reported NAc projections to LHb cells (40), although this has to be confirmed. Furthermore, the medial prefrontal cortex (mPFC) receives DAergic fibers from the medial VTA and sends glutamatergic projections to the NAc and LHb $[(36,39,41)$; Figure 1].

The VTA is known to be a DAergic source, although some VTA neurons also contain GABA and glutamate. In this regard, some studies reported that the LHb is innervated by DAergic fibers and also by glutamate and GABAergic projections from the medial and lateral part of the VTA, respectively (42-45). In humans, there is a functional correlation between the LHb and VTA during aversion process, indicating a strong coupling of these structures (46). Thus, VTA-GABAergic transmission to the LHb may encode reward, while glutamatergic transmission results in aversion [(47); Figures 1A,B].

LHb neurons, which are mainly glutamatergic, are activated by an aversive cue, an unrewarding task or an error of prediction (i.e., absence of expected reward), and they are inhibited by an expected or unexpected reward $(32,48)$. Interestingly, DAergic VTA neurons behave the other way round in the presence of a reward or an aversive stimulus $(32,49,50)$. Glutamatergic LHb 

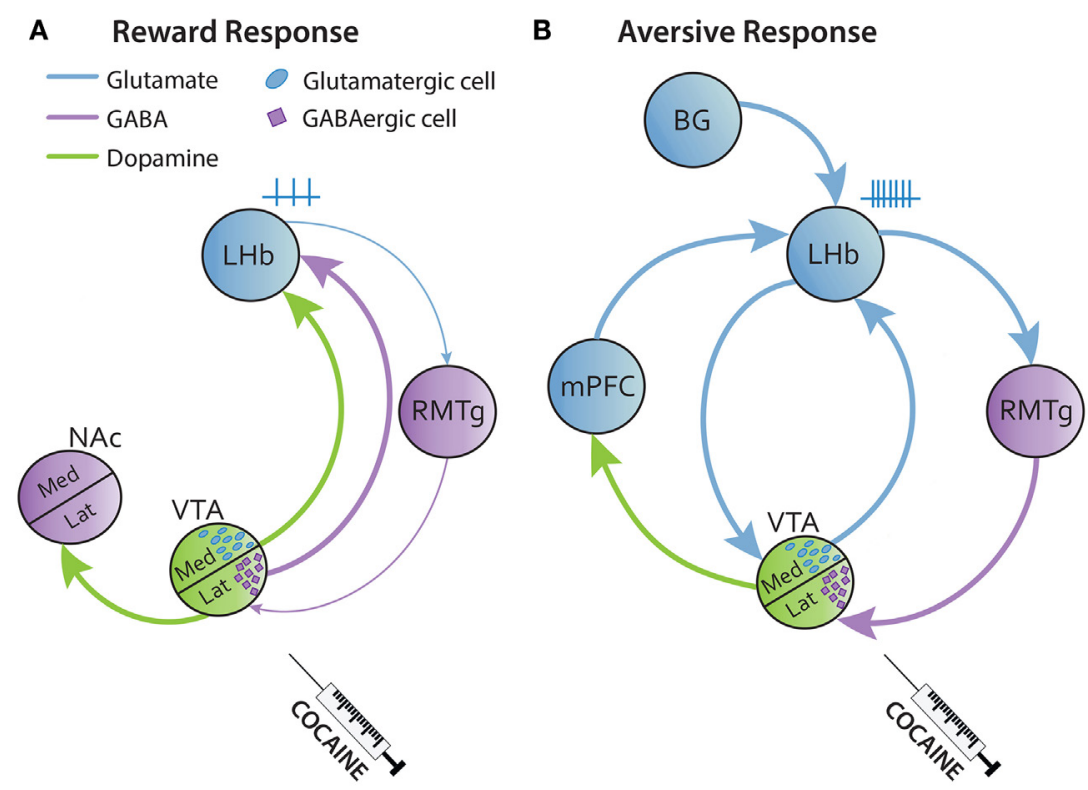

FIGURE 1 | Simplified circuitry of reward and aversive responses of the LHb to drug intake. (A) Acute injections of cocaine activate the lateral VTA inducing $\mathrm{DA}$ release to the lateral NAc (shell) leading in a reward response. The LHb receives GABAergic and DAergic fibers from the VTA that inhibit the LHb. (B) Cocaine also has a delayed aversive effect that follows the reward response. Here, the LHb is activated by several glutamatergic excitatory inputs from BG, mPFC, and medial VTA that will be facilitated by cocaine. BG, basal ganglia; Med, median; mPFC, medial prefrontal cortex; Lat, lateral.

projections terminate mostly on the rostromedial tegmentum nucleus (RMTg), which is a GABAergic nucleus inhibiting the lateral VTA, which then projects to the NAc $(41,51)$. Thus, the LHb-RMTg-VTA circuit predicts appetitive or aversive outcomes. There are also few LHb glutamatergic fibers directly innervating DAergic neurons of the medial VTA which modulate the activity of the mPFC to drive aversion $[(41,43,51)$; Figures 1A,B].

Cocaine intake has an initial rewarding effect, which depends on the DAergic circuit to the NAc, which is followed by a negative effect in which glutamate might play an important role. Due to the close functional relationship of the $\mathrm{LHb}$ with the DAergic reward system, its implication in positive and negative effects of drug intake has been extensively studied. The LHb is a structure very sensitive to cocaine. A low dose of cocaine increases the glucose uptake in this region in rats (52). In vivo and in vitro cocaine exposure leads to an inhibitory (reward effect) or a biphasic firing rate response of the LHb. This LHb biphasic response (inhibitory then an excitatory effect) represents the reward and aversive states after cocaine intake, respectively [(53); Figures 1A,B]. Moreover, cocaine induces an increase of AMPA receptors in the LHb that facilitates glutamatergic inputs (from the VTA, basal ganglia, or mPFC), leading to LHb hyperactivity and hyperexcitability (Figure 1B). This LHb hyperactivity might have a feedback role to prevent a higher activation of the VTA $[(36,43,54-59)$; Figure 1B].

The role of the LHb in drug intake has also been highlighted in studies using lesions. LHb-ablated animals do not extinct drugseeking behavior while cocaine intake is not affected, suggesting that animals are not able to decrease drug-seeking even if there are no more rewarding effects (60). Voluntary ethanol intake is higher in rats with $\mathrm{LHb}$ lesions than that in sham control animals (61). In sum, these results show the important role of the LHb in the regulation of drug-directed behaviors and in the mediation of drug intake effects.

The $\mathrm{MHb}$ seems to play a role in the regulation of behavior and drug addiction as well. Mainly the $\mathrm{MHb}$ has been implicated in nicotine addiction (62). However, in mice with lesions of the dorsal part of the $\mathrm{MHb}$, voluntary motor activity and sucrose preference are affected, suggesting an important role of the $\mathrm{MHb}$ in diverse motivated behaviors (63). Moreover, $\mathrm{MHb}$ inhibition by the antagonists of nicotinic receptors or optogenetic manipulations blocks drug self-administration (e.g., cocaine, morphine, alcohol) or leads to an aversive response, respectively $(62,63)$.

Hence, habenular nuclei ( $\mathrm{LHb}$ and $\mathrm{MHb}$ ) may have different impact on behavior and drug intake. This difference might depend on their particular function, the circadian properties of each structure (i.e., period, phase, and amplitude), and/or the time of drug exposure.

\section{The Circadian Clock in the Lateral Habenula}

Beyond the role of the $\mathrm{Hb}$ on behavioral control, recent data have shown an implication of the $\mathrm{Hb}$ in the regulation of sleep and circadian rhythms. Electrophysiological recordings showed that both $\mathrm{LHb}$ and $\mathrm{MHb}$ cells present a circadian variation of their spontaneous firing rate [(64-67); Figure 2]. This rhythmic activity disappears in both the $\mathrm{MHb}$ and $\mathrm{LHb}$ in animals with a molecular circadian clock mutation $(65,66)$. 


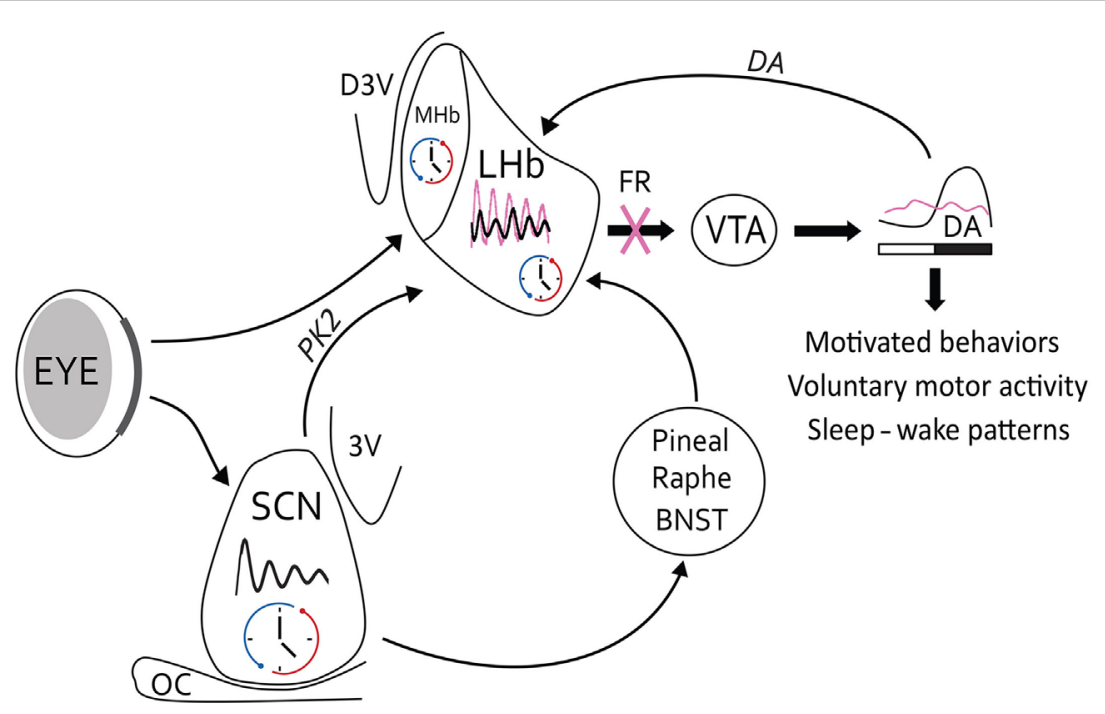

FIGURE 2 | Circadian circuitry of LHb for the control of behavior. The circadian oscillator in the LHb may be affected by light information from retinal projections (in bold), which arrive at the border of the LHb. The main SCN clock contacts the LHb by a direct neural pathway in which PK2 is positioned as the main clock-output factor. However, possible indirect pathways via the pineal gland, raphe nuclei, or BNST may link the SCN to the LHb as well. The LHB modulates midbrain DA activity from the VTA, and reciprocally DA may affect LHb activity. Under normal conditions (black oscillation), this pathway may result in a circadian release of DA in the striatum and several behavioral outputs, such as motivated behavior, voluntary motor activity, or sleep-wake cycles. On the other hand, under acute cocaine conditions, circadian rhythms of the LHb may change in amplitude, phase, or period (pink oscillations), which can lead in modifications of the VTA activity. However, under chronic cocaine situations beyond changes in LHb oscillations, denervations of the FR (pink cross) may lead to a dysregulation in the DAergic system and related behavioral outputs. Thus, symptoms of addictive behaviors may appear due to loss of rhythmic control of LHb. $3 \mathrm{~V}$, ventral third ventricule; BNST, bed nucleus of the stria terminalis; D3V, dorsal third ventricule; OC, optic chiasma.

Other studies report the expression of Per1-2 and Clock mRNA and protein in the whole Hb complex $(68,69)$. Using transgenic mice in which a luciferase reporter is coupled to the protein PER2, authors showed that the expression of PER2 in a small selected part in the mid-LHb has a sustained rhythmic activity (64). Moreover, c-Fos expression in the LHb is also rhythmic in mice, hamsters, and rats (70). Interestingly, denervations of the FR, the main output of the LHb, alter the circadian rest-activity cycle in hamsters (71). Thus, the LHb clock modulates the intensity or amount of activity in the day-night rhythms of locomotion.

The LHb receives environmental light information from melanopsin ganglion cells of the retina that project to the border of the LHb; thus, some interneurons may link the retino-LHb pathway [(72); Figure 2]. In addition, firing rate of LHb cells is affected by light in vivo, and this photic response is significantly larger in amplitude in LHb cells during the night than during the day (67).

The SCN clock innervates the LHb (Figure 2). The SCN uses different neuropeptide, such as vasopressin, vasoactive intestinal peptide, and prokineticin 2 (PK2), to communicate time information to other brain structures (73). The LHb receives PK2 fibers from the SCN and contains PK2 receptors [(74); Figure 2]. A recent study reported that PK2 is able to inhibit the $\mathrm{LHb}$ firing rate in vitro (66). Some vasopressin fibers run around the ventral part of the LHb even in SCN-lesioned rats, suggesting that vasopressin source might come from other brain structure (75); the bed nucleus of the stria terminalis, or the paraventricular nucleus of the hypothalamus (76) for example.
An indirect pathway can drive the message from the SCN to the LHb by a hormonal input (e.g., melatonin), or by a neuronal pathway with an intermediate structure, such as the raphe nuclei that project to both the SCN and LHb [(77-79); Figure 2]. Interestingly, serotonin release from the raphe nuclei is also rhythmic; it modulates SCN activity and dampens excitatory inputs from the basal ganglia to the LHb (54, 80, 81). Thus, serotonin may be a good candidate to modulate the rhythmic activity of the LHb. Reciprocally, the LHb projects to the raphe nuclei (82), and drugs of abuse act on serotonin transporters (83). Serotonin levels are altered in depression and mood signs are often associated symptoms of addicted behaviors. Therefore, the mood changes during addiction may be dependent on disturbance in the circadian link between the LHb and the raphe nuclei (84).

\section{What May Be the Clock-Outputs of the LHb to Control Rhythmic Drug Intake?}

The VTA expresses clock genes and tyrosine hydroxylase (the limiting enzyme in DA synthesis) co-localizes with clock proteins [REV-ERB, BMAL1, PER1; (85-87)]. DA release and cell firing in the VTA are rhythmic (88-90). Moreover, the PER2 protein expression in the striatum follows a circadian rhythm (peak of expression rises at night) that is entrained by DA via D2 type receptors (91). However, in isolated cultured VTA from Per1: Luciferase rats, no oscillations were found (92). Thus, VTA circadian oscillations must be under the control of a brain selfsustained circadian oscillator. 
Day-night differences of tyrosine hydroxylase and DA transporter in striatum are dampened but not abolished in SCNlesioned rats (93). Therefore, another circadian clock beyond the $\mathrm{SCN}$ regulates rhythmic activity of the DAergic system. The LHb clock could play an important role for the regulation of DAergic rhythms (Figure 2).

The circadian role of the $\mathrm{LHb}$ might be to inhibit DAergic neurons at a specific time during the 24-h cycle. In rats, the LHb peak of electrical activity occurs during the day, when the release of DA to the striatum is low $(67,91)$. In mice, however, there is a circadian rhythm of LHb firing rate with a peak at night time, which correlates with VTA lower electrical activity (64, 94). Thus, it is necessary to determine the circadian activity (i.e., firing rate, clock gene expression) of the LHb in vivo in both rats and mice.

Since LHb activity controls DA neuronal activity, it is also possible that $\mathrm{LHb}$ modulates rhythmic behaviors related to drug intake through the regulation of the DAergic system. In fact, behavioral sensitization [which has a rhythmic profile; (15, 16)] is altered by LHb lesions in rats (95). This suggests that the LHb clock could modulate the rhythmic patterns of behavioral sensitization or reward effects of cocaine. Moreover, cocaine selfadministration shows a daily rhythm in phase (with a maximum at the night) with the peak of DA release in the striatum. Both self-administration and DA release are correlated with the highest $\mathrm{LHb}$ firing rate $(20,23,67,91)$. Importantly, chronic intake of cocaine, which leads to FR degeneration, is able to disrupt circadian rhythms probably due to the lack of LHb control on monoamine nuclei $[(20,96)$; Figure 2].

\section{Possible Therapies for Addiction: The Habenula as a Target}

Low frequency stimulations, which mimic inputs from the VTA or raphe nucleus to the $\mathrm{LHb}$, inhibit the $\mathrm{LHb}$ activity and induce cocaine intake in rats $(35-38,60)$. However, high frequencies, which mimic aversive and excitatory input from the basal ganglia, do not reduce cocaine intake (35-38, 60). Interestingly, deep brain stimulation (DBS) is associated with reward and aversive inputs (low and high frequencies), and reduces cocaine consumption in rats (60). DBS is a technical approach that has been used for the treatment of some psychiatric disorders, such as depression and obsessive-compulsive disorder (97).

The LHb has been proposed as a target for DBS to treat addiction because of its close functional relationship with the reward system (98). However, chronic exposure to cocaine, amphetamine, methamphetamine, MDMA, or nicotine results in the degeneration of the FR, which blocks the effect of DBS on drug intake $(96,99,100)$. As long as FR is able to transmit information, the LHb can be considered as a main target for DBS in the treatment of addiction. Moreover, if circadian properties of the LHb are an important factor for DBS, it then becomes possible to potentiate the beneficial effect, or avoid side effects of DBS, by applying stimulation at a specific time of the day and consider a genuine type of DBS chronotherapy (i.e., timedependent treatment).
Despite the prominent actions of DBS as a treatment, the technique still remains an invasive approach that may produce side effects. Therefore, other alternative treatments for addiction have to be considered.

In chronic drug intake, degeneration of FR may be due, in part, to a reduction of the GABA receptors expression, leading to a $\mathrm{LHb}$ disinhibition, and an increase of glutamate receptors allowing an excitotoxic effect on LHb cells $(58,96,99)$. LHb disinhibition may be restored by a $\mathrm{GABA}_{\mathrm{B}}$ receptor agonist, a molecule that is already proposed as a possible treatment for drug addiction (101). Hence, LHb inhibition by GABA agonists at the circadian optimal time could rescue a daily rhythm of LHb activity and reduce addiction states.

The $\mathrm{Hb}$ expresses melatonin receptors (102) and projects to the pineal gland, the site of melatonin production (103). Melatonin receptors mediate the behavioral sensitization to methamphetamine (104). Moreover, activation of melatonin receptors (with melatonin or the agonist agomelatine) reduces relapse-like alcohol intake in rats (105). More importantly, since there is a strong rhythmic activity of melatonin, it is possible that the effects of the hormone on the circadian activity of the Hb are phase (time)-dependent. Thus, melatonin might have effects to modulate drug-seeking and intake via an activation of its receptors in the $\mathrm{Hb}$ at specific times of the day.

\section{CONCLUSION}

In this review, we addressed the circadian relevance of the $\mathrm{LHb}$ for the regulation of rhythmic brain activity and behavior. This work may help to understand the role of LHb, as a circadian clock, in the development of psychiatric pathologies and addiction. The vast literature devoted to $\mathrm{LHb}$ indicates that these nuclei have a relevant role in different brain functions, and dysfunctions (e.g., depression and addiction) (106). Some studies also highlight the clock properties of the LHb in the regulation of behavior $(70,71,107)$. Therefore, to understand the specific neurobiological role of the $\mathrm{Hb}$ (both the $\mathrm{MHb}$ and $\mathrm{LHb}$ nuclei) in brain physiology and pathophysiological conditions, the circadian properties of this brain locus should be considered as an important factor.

\section{ACKNOWLEDGMENTS}

We would like to thank Dr. Matthew Beymer, Dr. Domitille Boudard, and Milagros M Arietti for comments and suggestions on the manuscript. We thank the three reviewers for all the comments and suggestions that certainly improved our manuscript.

\section{FUNDING}

This work was supported by Agence Nationale de la Recherche (grant ANR-14-CE13-0002-01 ADDiCLOCK JCJC to JM and NLS PhD fellow) and the Centre Nationale de la Recherche Scientifique (CNRS). 


\section{REFERENCES}

1. Pittendrigh CS. Temporal organization: reflections of a Darwinian clock-watcher. Annu Rev Physiol (1993) 55:16-54. doi:10.1146/annurev. ph.55.030193.000313

2. Welsh DK, Takahashi JS, Kay SA. Suprachiasmatic nucleus: cell autonomy and network properties. Annu Rev Physiol (2010) 72:551-77. doi:10.1146/ annurev-physiol-021909-135919

3. Takahashi JS, Hong H-K, Ko CH, McDearmon EL. The genetics of mammalian circadian order and disorder: implications for physiology and disease. Nat Rev Genet (2008) 9:764-75. doi:10.1038/nrg2430

4. Lucas RJ, Lall GS, Allen AE, Brown TM. How rod, cone, and melanopsin photoreceptors come together to enlighten the mammalian circadian clock. Prog Brain Res (2012) 199:1-18. doi:10.1016/B978-0-444-59427-3.00001-0

5. Honma K, Honma S. The SCN-independent clocks, methamphetamine and food restriction. Eur J Neurosci (2009) 30:1707-17. doi:10.1111/j.1460-9568.2009.06976.x

6. Glass JD, Brager AJ, Stowie AC, Prosser RA. Cocaine modulates pathways for photic and nonphotic entrainment of the mammalian SCN circadian clock. Am J Physiol Regul Integr Comp Physiol (2012) 302:R740-50. doi:10.1152/ ajpregu.00602.2011

7. Hughes ATL, Piggins HD. Feedback actions of locomotor activity to the circadian clock. Prog Brain Res (2012) 199:305-36. doi:10.1016/ B978-0-444-59427-3.00018-6

8. Kosobud AEK, Gillman AG, Leffel JK, Pecoraro NC, Rebec GV, Timberlake W. Drugs of abuse can entrain circadian rhythms. ScientificWorldJournal (2007) 7:203-12. doi:10.1100/tsw.2007.234

9. Stowie AC, Amicarelli MJ, Prosser RA, Glass JD. Chronic cocaine causes longterm alterations in circadian period and photic entrainment in the mouse. Neuroscience (2015) 284:171-9. doi:10.1016/j.neuroscience.2014.08.057

10. Kirkpatrick MG, Haney M, Vosburg SK, Comer SD, Foltin RW, Hart CL. Methamphetamine self-administration by humans subjected to abrupt shift and sleep schedule changes. Psychopharmacology (Berl) (2009) 203:771-80. doi:10.1007/s00213-008-1423-1

11. Doyle SE, Feng H, Garber G, Menaker M, Lynch WJ. Effects of circadian disruption on methamphetamine consumption in methamphetamine-exposed rats. Psychopharmacology (Berl) (2015) 232:2169-79. doi:10.1007/ s00213-014-3845-2

12. Morris RW. Circadian and circannual rhythms of emergency room drug-overdose admissions. Prog Clin Biol Res (1987) 227B:451-7.

13. Raymond RC, Warren M, Morris RW, Leikin JB. Periodicity of presentations of drugs of abuse and overdose in an emergency department. J Toxicol Clin Toxicol (1992) 30:467-78. doi:10.3109/15563659209021561

14. Erickson TB, Lee J, Zautcke JL, Morris R. Analysis of cocaine chronotoxicology in an urban ED. Am J Emerg Med (1998) 16:568-71. doi:10.1016/ S0735-6757(98)90220-0

15. Abarca C, Albrecht U, Spanagel R. Cocaine sensitization and reward are under the influence of circadian genes and rhythm. Proc Natl Acad Sci U S A (2002) 99:9026-30. doi:10.1073/pnas.142039099

16. Uz T, Javaid JI, Manev H. Circadian differences in behavioral sensitization to cocaine: putative role of arylalkylamine N-acetyltransferase. Life Sci (2002) 70:3069-75. doi:10.1016/S0024-3205(02)01559-X

17. Uz T, Akhisaroglu M, Ahmed R, Manev $H$. The pineal gland is critical for circadian Period 1 expression in the striatum and for circadian cocaine sensitization in mice. Neuropsychopharmacology (2003) 28:2117-23. doi:10.1038/ sj.npp. 1300254

18. Akhisaroglu M, Ahmed R, Kurtuncu M, Manev H, Uz T. Diurnal rhythms in cocaine sensitization and in Period 1 levels are common across rodent species. Pharmacol Biochem Behav (2004) 79:37-42. doi:10.1016/j.pbb.2004.06.014

19. Kurtuncu M, Arslan AD, Akhisaroglu M, Manev H, Uz T. Involvement of the pineal gland in diurnal cocaine reward in mice. Eur J Pharmacol (2004) 489:203-5. doi:10.1016/j.ejphar.2004.03.010

20. Morgan D, Roberts DCS. Sensitization to the reinforcing effects of cocaine following binge-abstinent self-administration. Neurosci Biobehav Rev (2004) 27:803-12. doi:10.1016/j.neubiorev.2003.11.004

21. Rosenwasser AM, Fecteau ME, Logan RW. Effects of ethanol intake and ethanol withdrawal on free-running circadian activity rhythms in rats. Physiol Behav (2005) 84:537-42. doi:10.1016/j.physbeh.2005.01.016
22. Perreau-Lenz S, Vengeliene V, Noori HR, Merlo-Pich EV, Corsi MA, Corti $\mathrm{C}$, et al. Inhibition of the casein-kinase-1- $\varepsilon / \delta /$ prevents relapse-like alcohol drinking. Neuropsychopharmacology (2012) 37:2121-31. doi:10.1038/ npp. 2012.62

23. Bass CE, Jansen HT, Roberts DCS. Free-running rhythms of cocaine self-administration in rats held under constant lighting conditions. Chronobiol Int (2010) 27:535-48. doi:10.3109/07420521003664221

24. Spanagel R, Pendyala G, Abarca C, Zghoul T, Sanchis-Segura C, Magnone $\mathrm{MC}$, et al. The clock gene Per2 influences the glutamatergic system and modulates alcohol consumption. Nat Med (2005) 11:35-42. doi:10.1038/nm1163

25. Falcón E, McClung CA. A role for the circadian genes in drug addiction. Neuropharmacology (2009) 56(Suppl 1):91-6. doi:10.1016/j. neuropharm.2008.06.054

26. Ozburn AR, Falcon E, Mukherjee S, Gillman A, Arey R, Spencer S, et al. The role of clock in ethanol-related behaviors. Neuropsychopharmacology (2013) 38:2393-400. doi:10.1038/npp.2013.138

27. Ozburn AR, Falcon E, Twaddle A, Nugent AL, Gillman AG, Spencer SM, et al. Direct regulation of diurnal Drd3 expression and cocaine reward by NPAS2. Biol Psychiatry (2015) 77:425-33. doi:10.1016/j.biopsych.2014.07.030

28. Albrecht U. Timing to perfection: the biology of central and peripheral circadian clocks. Neuron (2012) 74:246-60. doi:10.1016/j.neuron.2012.04.006

29. Guilding C, Piggins HD. Challenging the omnipotence of the suprachiasmatic timekeeper:are circadian oscillatorspresent throughout the mammalianbrain? Eur J Neurosci (2007) 25:3195-216. doi:10.1111/j.1460-9568.2007.05581.x

30. Webb IC, Lehman MN, Coolen LM. Diurnal and circadian regulation of reward-related neurophysiology and behavior. Physiol Behav (2015) 143:58-69. doi:10.1016/j.physbeh.2015.02.034

31. Mendoza J, Challet E. Circadian insights into dopamine mechanisms. Neuroscience (2014) 282C:230-42. doi:10.1016/j.neuroscience.2014.07.081

32. Matsumoto M, Hikosaka O. Lateral habenula as a source of negative reward signals in dopamine neurons. Nature (2007) 447:1111-5. doi:10.1038/ nature 05860

33. Aizawa H, Kobayashi M, Tanaka S, Fukai T, Okamoto H. Molecular characterization of the subnuclei in rat habenula. J Comp Neurol (2012) 520:4051-66. doi:10.1002/cne.23167

34. Andres KH, von Düring $\mathrm{M}$, Veh RW. Subnuclear organization of the rat habenular complexes. J Comp Neurol (1999) 407:130-50. doi:10.1002/ (SICI)1096-9861(19990428)407:1<130::AID-CNE10>3.0.CO;2-8

35. Sutherland RJ. The dorsal diencephalic conduction system: a review of the anatomy and functions of the habenular complex. Neurosci Biobehav Rev (1982) 6:1-13. doi:10.1016/0149-7634(82)90003-3

36. Lecourtier L, Kelly PH. A conductor hidden in the orchestra? Role of the habenular complex in monoamine transmission and cognition. Neurosci Biobehav Rev (2007) 31:658-72. doi:10.1016/j.neubiorev.2007.01.004

37. Hikosaka O. The habenula: from stress evasion to value-based decision-making. Nat Rev Neurosci (2010) 11:503-13. doi:10.1038/nrn2866

38. Bianco IH, Wilson SW. The habenular nuclei: a conserved asymmetric relay station in the vertebrate brain. Philos Trans R Soc Lond B Biol Sci (2009) 364:1005-20. doi:10.1098/rstb.2008.0213

39. Russo SJ, Nestler EJ. The brain reward circuitry in mood disorders. Nat Rev Neurosci (2013) 14:609-25. doi:10.1038/nrn3381

40. Li YQ, Takada M, Mizuno N. Demonstration of habenular neurons which receive afferent fibers from the nucleus accumbens and send their axons to the midbrain periaqueductal gray. Neurosci Lett (1993) 158:55-8. doi:10.1016/0304-3940(93)90611-N

41. Lammel S, Lim BK, Ran C, Huang KW, Betley MJ, Tye KM, et al. Inputspecific control of reward and aversion in the ventral tegmental area. Nature (2012) 491:212-7. doi:10.1038/nature11527

42. Gruber C, Kahl A, Lebenheim L, Kowski A, Dittgen A, Veh RW. Dopaminergic projections from the VTA substantially contribute to the mesohabenular pathway in the rat. Neurosci Lett (2007) 427:165-70. doi:10.1016/j. neulet.2007.09.016

43. Hnasko TS, Hjelmstad GO, Fields HL, Edwards RH. Ventral tegmental area glutamate neurons: electrophysiological properties and projections. J Neurosci (2012) 32:15076-85. doi:10.1523/JNEUROSCI.3128-12.2012

44. Root DH, Mejias-Aponte CA, Zhang S, Wang H-L, Hoffman AF, Lupica CR, et al. Single rodent mesohabenular axons release glutamate and GABA. Nat Neurosci (2014) 17:1543-51. doi:10.1038/nn.3823 
45. Taylor SR, Badurek S, Dileone RJ, Nashmi R, Minichiello L, Picciotto MR. GABAergic and glutamatergic efferents of the mouse ventral tegmental area. J Comp Neurol (2014) 522:3308-34. doi:10.1002/cne.23603

46. Hennigan K, D’Ardenne K, McClure SM. Distinct midbrain and habenula pathways are involved in processing aversive events in humans. J Neurosci (2015) 35:198-208. doi:10.1523/JNEUROSCI.0927-14.2015

47. Root DH, Mejias-Aponte CA, Qi J, Morales M. Role of glutamatergic projections from ventral tegmental area to lateral habenula in aversive conditioning. J Neurosci (2014) 34:13906-10. doi:10.1523/JNEUROSCI.2029-14.2014

48. Matsumoto M, Hikosaka O. Representation of negative motivational value in the primate lateral habenula. Nat Neurosci (2009) 12:77-84. doi:10.1038/ nn. 2233

49. Matsumoto M, Hikosaka O. Two types of dopamine neuron distinctly convey positive and negative motivational signals. Nature (2009) 459:837-41. doi:10.1038/nature08028

50. Shumake J, Ilango A, Scheich H, Wetzel W, Ohl FW. Differential neuromodulation of acquisition and retrieval of avoidance learning by the lateral habenula and ventral tegmental area. J Neurosci (2010) 30:5876-83. doi:10.1523/JNEUROSCI.3604-09.2010

51. Brinschwitz K, Dittgen A, Madai VI, Lommel R, Geisler S, Veh RW. Glutamatergic axons from the lateral habenula mainly terminate on GABAergic neurons of the ventral midbrain. Neuroscience (2010) 168:463-76. doi:10.1016/j.neuroscience.2010.03.050

52. London ED, Wilkerson G, Goldberg SR, Risner ME. Effects of L-cocaine on local cerebral glucose utilization in the rat. Neurosci Lett (1986) 68:73-8. doi:10.1016/0304-3940(86)90232-6

53. Jhou TC, Good CH, Rowley CS, Xu S-P, Wang H, Burnham NW, et al. Cocaine drives aversive conditioning via delayed activation of dopamine-responsive habenular and midbrain pathways. J Neurosci (2013) 33:7501-12. doi:10.1523/JNEUROSCI.3634-12.2013

54. Shabel SJ, Proulx CD, Trias A, Murphy RT, Malinow R. Input to the lateral habenula from the basal ganglia is excitatory, aversive, and suppressed by serotonin. Neuron (2012) 74:475-81. doi:10.1016/j.neuron.2012.02.037

55. Maroteaux M, Mameli M. Cocaine evokes projection-specific synaptic plasticity of lateral habenula neurons. J Neurosci (2012) 32:12641-6. doi:10.1523/ JNEUROSCI.2405-12.2012

56. Zuo W, Chen L, Wang L, Ye J-H. Cocaine facilitates glutamatergic transmission and activates lateral habenular neurons. Neuropharmacology (2013) 70:180-9. doi:10.1016/j.neuropharm.2013.01.008

57. Neumann PA, Ishikawa M, Otaka M, Huang YH, Schlüter OM, Dong Y. Increased excitability of lateral habenula neurons in adolescent rats following cocaine self-administration. Int J Neuropsychopharmacol (2015) 18:pyu109. doi:10.1093/ijnp/pyu109

58. Meye FJ, Valentinova K, Lecca S, Marion-Poll L, Maroteaux MJ, Musardo $\mathrm{S}$, et al. Cocaine-evoked negative symptoms require AMPA receptor trafficking in the lateral habenula. Nat Neurosci (2015) 18:376-8. doi: $10.1038 / \mathrm{nn} .3923$

59. Shen X, Ruan X, Zhao H. Stimulation of midbrain dopaminergic structures modifies firing rates of rat lateral habenula neurons. PLoS One (2012) 7:e34323. doi:10.1371/journal.pone.0034323

60. Friedman A, Lax E, Dikshtein Y, Abraham L, Flaumenhaft Y, Sudai E, et al. Electrical stimulation of the lateral habenula produces enduring inhibitory effect on cocaine seeking behavior. Neuropharmacology (2010) 59:452-9. doi:10.1016/j.neuropharm.2010.06.008

61. Haack AK, Sheth C, Schwager AL, Sinclair MS, Tandon S, Taha SA. Lesions of the lateral habenula increase voluntary ethanol consumption and operant self-administration, block yohimbine-induced reinstatement of ethanol seeking, and attenuate ethanol-induced conditioned taste aversion. PLoS One (2014) 9:e92701. doi:10.1371/journal.pone.0092701

62. Viswanath H, Carter AQ, Baldwin PR, Molfese DL, Salas R. The medial habenula: still neglected. Front Hum Neurosci (2014) 7:931. doi:10.3389/ fnhum.2013.00931

63. Hsu Y-WA, Wang SD, Wang S, Morton G, Zariwala HA, de la Iglesia HO, et al. Role of the dorsal medial habenula in the regulation of voluntary activity, motor function, hedonic state, and primary reinforcement. J Neurosci (2014) 34:11366-84. doi:10.1523/JNEUROSCI.1861-14.2014

64. Guilding C, Hughes ATL, Piggins HD. Circadian oscillators in the epithalamus. Neuroscience (2010) 169:1630-9. doi:10.1016/j.neuroscience.2010.06.015
65. Sakhi K, Belle MDC, Gossan N, Delagrange P, Piggins HD. Daily variation in the electrophysiological activity of mouse medial habenula neurones. $J$ Physiol (2014) 592:587-603. doi:10.1113/jphysiol.2013.263319

66. Sakhi K, Wegner S, Belle MDC, Howarth M, Delagrange P, Brown TM, et al. Intrinsic and extrinsic cues regulate the daily profile of mouse lateral habenula neuronal activity. J Physiol (2014) 592:5025-45. doi:10.1113/ jphysiol.2014.280065

67. Zhao H, Rusak B. Circadian firing-rate rhythms and light responses of rat habenular nucleus neurons in vivo and in vitro. Neuroscience (2005) 132:519-28. doi:10.1016/j.neuroscience.2005.01.012

68. Shieh K-R. Distribution of the rhythm-related genes rPERIOD1, rPERIOD2, and rCLOCK, in the rat brain. Neuroscience (2003) 118:831-43. doi:10.1016/ S0306-4522(03)00004-6

69. Zhao Z, Xu H, Liu Y, Mu L, Xiao J, Zhao H. Diurnal expression of the Per2 gene and protein in the lateral habenular nucleus. Int J Mol Sci (2015) 16:16740-9. doi:10.3390/ijms160816740

70. Tavakoli-Nezhad M, Schwartz WJ. Hamsters running on time: is the lateral habenula a part of the clock? Chronobiol Int (2006) 23:217-24. doi:10.1080/07420520500521947

71. Paul MJ, Indic P, Schwartz WJ. A role for the habenula in the regulation of locomotor activity cycles. Eur J Neurosci (2011) 34:478-88. doi:10.1111/j.1460-9568.2011.07762.x

72. Hattar S, Kumar M, Park A, Tong P, Tung J, Yau K-W, et al. Central projections of melanopsin-expressing retinal ganglion cells in the mouse. J Comp Neurol (2006) 497:326-49. doi:10.1002/cne.20970

73. Kalsbeek A, Palm IF, La Fleur SE, Scheer FA, Perreau-Lenz S, Ruiter M, et al. SCN outputs and the hypothalamic balance of life. J Biol Rhythms (2006) 21:458-69. doi:10.1177/0748730406293854

74. Zhang C, Truong KK, Zhou Q-Y. Efferent projections of prokineticin 2 expressing neurons in the mouse suprachiasmatic nucleus. PLoS One (2009) 4:e7151. doi:10.1371/journal.pone.0007151

75. Hoorneman EM, Buijs RM. Vasopressin fiber pathways in the rat brain following suprachiasmatic nucleus lesioning. Brain Res (1982) 243:235-41. doi:10.1016/0006-8993(82)90246-3

76. Hernández VS, Vázquez-Juárez E, Márquez MM, Jáuregui-Huerta F, Barrio RA, Zhang L. Extra-neurohypophyseal axonal projections from individual vasopressin-containing magnocellular neurons in rat hypothalamus. Front Neuroanat (2015) 9:130. doi:10.3389/fnana.2015.00130

77. Leak RK, Moore RY. Topographic organization of suprachiasmatic nucleus projection neurons. J Comp Neurol (2001) 433:312-34. doi:10.1002/cne.1142

78. Kalsbeek A, Palm IF, Buijs RM. Central vasopressin systems and steroid hormones. Prog Brain Res (2002) 139:57-73. doi:10.1016/ S0079-6123(02)39007-1

79. Vertes RP, Linley SB. Efferent and afferent connections of the dorsal and median raphe nuclei in the rat. In: Monti JM, Pandi-Perumal SR, Jacobs BL, Nutt DJ, editors. Serotonin and Sleep: Molecular, Functional and Clinical Aspects. Basel: Birkhäuser (2008). p. 69-102.

80. Dudley TE, DiNardo LA, Glass JD. Endogenous regulation of serotonin release in the hamster suprachiasmatic nucleus. J Neurosci (1998) 18:5045-52.

81. Glass JD, DiNardo LA, Ehlen JC. Dorsal raphe nuclear stimulation of SCN serotonin release and circadian phase-resetting. Brain Res (2000) 859:224-32. doi:10.1016/S0006-8993(00)01963-6

82. Aghajanian GK, Wang RY. Habenular and other midbrain raphe afferents demonstrated by a modified retrograde tracing technique. Brain Res (1977) 122:229-42. doi:10.1016/0006-8993(77)90291-8

83. Hall FS, Sora I, Drgonova J, Li X-F, Goeb M, Uhl GR. Molecular mechanisms underlying the rewarding effects of cocaine. Ann N Y Acad Sci (2004) 1025:47-56. doi:10.1196/annals.1316.006

84. Zhao H, Zhang B-L, Yang S-J, Rusak B. The role of lateral habenula-dorsal raphe nucleus circuits in higher brain functions and psychiatric illness. Behav Brain Res (2015) 277:89-98. doi:10.1016/j.bbr.2014.09.016

85. McClung CA, Sidiropoulou K, Vitaterna M, Takahashi JS, White FJ, Cooper $\mathrm{DC}$, et al. Regulation of dopaminergic transmission and cocaine reward by the Clock gene. Proc Natl Acad Sci U S A (2005) 102:9377-81. doi:10.1073/ pnas.0503584102

86. Imbesi M, Yildiz S, Dirim Arslan A, Sharma R, Manev H, Uz T. Dopamine receptor-mediated regulation of neuronal "clock" gene expression. Neuroscience (2009) 158:537-44. doi:10.1016/j.neuroscience.2008.10.044 
87. Chung S, Lee EJ, Yun S, Choe HK, Park S-B, Son HJ, et al. Impact of circadian nuclear receptor REV-ERB $\alpha$ on midbrain dopamine production and mood regulation. Cell (2014) 157:858-68. doi:10.1016/j.cell.2014.03.039

88. Schade R, Vick K, Ott T, Sohr R, Pfister C, Bellach J, et al. Circadian rhythms of dopamine and cholecystokinin in nucleus accumbens and striatum of rats - influence on dopaminergic stimulation. Chronobiol Int (1995) 12:87-99. doi:10.3109/07420529509064504

89. Shieh KR, Chu YS, Pan JT. Circadian change of dopaminergic neuron activity: effects of constant light and melatonin. Neuroreport (1997) 8:2283-7. doi:10.1097/00001756-199707070-00037

90. Luo AH, Georges FE, Aston-Jones GS. Novel neurons in ventral tegmental area fire selectively during the active phase of the diurnal cycle. Eur J Neurosci (2008) 27:408-22. doi:10.1111/j.1460-9568.2007.05985.x

91. Hood S, Cassidy P, Cossette M-P, Weigl Y, Verwey M, Robinson B, et al. Endogenous dopamine regulates the rhythm of expression of the clock protein PER2 in the rat dorsal striatum via daily activation of D2 dopamine receptors. J Neurosci (2010) 30:14046-58. doi:10.1523/JNEUROSCI.2128-10.2010

92. Abe M, Herzog ED, Yamazaki S, Straume M, Tei H, Sakaki Y, et al. Circadian rhythms in isolated brain regions. J Neurosci (2002) 22:350-6.

93. Sleipness EP, Sorg BA, Jansen HT. Diurnal differences in dopamine transporter and tyrosine hydroxylase levels in rat brain: dependence on the suprachiasmatic nucleus. Brain Res (2007) 1129:34-42. doi:10.1016/j. brainres.2006.10.063

94. Stowie AC, Prosser RA, Glass JD. Cocaine modulation of the mammalian circadian clock: potential therapeutic targets. Ther Targets Neurol Dis (2015) 2:e607. doi:10.14800/ttnd.607

95. Gifuni AJ, Jozaghi S, Gauthier-Lamer A-C, Boye SM. Lesions of the lateral habenula dissociate the reward-enhancing and locomotor-stimulant effects of amphetamine. Neuropharmacology (2012) 63:945-57. doi:10.1016/j. neuropharm.2012.07.032

96. Ellison G, Irwin S, Keys A, Noguchi K, Sulur G. The neurotoxic effects of continuous cocaine and amphetamine in Habenula: implications for the substrates of psychosis. NIDA Res Monogr (1996) 163:117-45.

97. Udupa K, Chen R. The mechanisms of action of deep brain stimulation and ideas for the future development. Prog Neurobiol (2015) 133:27-49. doi:10.1016/j.pneurobio.2015.08.001

98. Pierce RC, Vassoler FM. Deep brain stimulation for the treatment of addiction: basic and clinical studies and potential mechanisms of action. Psychopharmacology (Berl) (2013) 229:487-91. doi:10.1007/ s00213-013-3214-6

99. Ellison G. Neural degeneration following chronic stimulant abuse reveals a weak link in brain, fasciculus retroflexus, implying the loss of forebrain control circuitry. Eur Neuropsychopharmacol (2002) 12:287-97. doi:10.1016/ S0924-977X(02)00020-2

100. Lax E, Friedman A, Croitoru O, Sudai E, Ben-Moshe H, Redlus L, et al. Neurodegeneration of lateral habenula efferent fibers after intermittent cocaine administration: implications for deep brain stimulation. Neuropharmacology (2013) 75:246-54. doi:10.1016/j.neuropharm.2013.06.034

101. Cousins MS, Roberts DCS, de Wit HGABA. (B) receptor agonists for the treatment of drug addiction: a review of recent findings. Drug Alcohol Depend (2002) 65:209-20. doi:10.1016/S0376-8716(01)00163-6

102. Lacoste B, Angeloni D, Dominguez-Lopez S, Calderoni S, Mauro A, Fraschini F, et al. Anatomical and cellular localization of melatonin MT1 and MT2 receptors in the adult rat brain. J Pineal Res (2015) 58:397-417. doi:10.1111/ jpi. 12224

103. Rønnekleiv OK, Kelly MJ, Wuttke W. Single unit recordings in the rat pineal gland: evidence for habenulo-pineal neural connections. Exp Brain Res (1980) 39:187-92.

104. Hutchinson AJ, Hudson RL, Dubocovich ML. Genetic deletion of MT(1) and MT(2) melatonin receptors differentially abrogates the development and expression of methamphetamine-induced locomotor sensitization during the day and the night in $\mathrm{C} 3 \mathrm{H} / \mathrm{HeN}$ mice. J Pineal Res (2012) 53:399-409. doi:10.1111/j.1600-079X.2012.01010.x

105. Vengeliene V, Noori HR, Spanagel R. Activation of melatonin receptors reduces relapse-like alcohol consumption. Neuropsychopharmacology (2015) 40:2897-906. doi:10.1038/npp.2015.143

106. Lecca S, Meye FJ, Mameli M. The lateral habenula in addiction and depression: an anatomical, synaptic and behavioral overview. Eur J Neurosci (2014) 39:1170-8. doi:10.1111/ejn.12480

107. Chastrette N, Pfaff DW, Gibbs RB. Effects of daytime and nighttime stress on Fos-like immunoreactivity in the paraventricular nucleus of the hypothalamus, the habenula, and the posterior paraventricular nucleus of the thalamus. Brain Res (1991) 563:339-44. doi:10.1016/0006-8993(91)91559-J

Conflict of Interest Statement: The authors declare that the research was conducted in the absence of any commercial or financial relationships that could be construed as a potential conflict of interest.

Copyright (c) 2016 Salaberry and Mendoza. This is an open-access article distributed under the terms of the Creative Commons Attribution License (CC BY). The use, distribution or reproduction in other forums is permitted, provided the original author(s) or licensor are credited and that the original publication in this journal is cited, in accordance with accepted academic practice. No use, distribution or reproduction is permitted which does not comply with these terms. 